Original Article

\title{
A CROSS-SECTIONAL DESCRIPTIVE STUDY OF DEPRESSION AMONG PATIENTS ATTENDING THE CARDIOLOGY CLINIC OF A UNIVERSITY TEACHING HOSPITAL IN NORTH-CENTRAL NIGERIA
}

\author{
Agbir T.M, ${ }^{1}$ Okpara I.C, ${ }^{2}$ Mbaave P.T, ${ }^{2}$ Audu M.D, ${ }^{3}$ Obindo J.T, ${ }^{3}$ Goar S.G, ${ }^{3}$ Piwuna $C,{ }^{3}$ Akinjola O, ${ }^{1}$ Tungchama F.P ${ }^{3}$ Nwoga C, ${ }^{3}$ \\ Maigari $\mathbf{Y}^{3}$ \\ ${ }^{I}$ Department of Psychiatry and ${ }^{2}$ Department of Medicine, Benue State University Teaching Hospital, Makurdi. \\ ${ }^{3}$ Department of Psychiatry Jos University Teaching Hospital, Jos.
}

*Corresponding Author: Dr Agbir Terkura Michael, Department of Psychiatry, Benue State University Teaching Hospital, Makurdi.

Published: November $23^{\text {rd }} 2018$.

\begin{abstract}
Depression has been consistently associated with cardiovascular disease (CVD), it is also known to play an essential role in the initiation and exacerbation of CVD. This study was aimed to determine the prevalence and correlates of depression among patients attending the cardiology clinic of the Benue State University Teaching Hospital (BSUTH), Makurdi. The study was conducted among one hundred and six (106) consenting patients attending the cardiology unit of BSUTH from June to August 2017. The result shows that, 52(49.1\%) were males while the remaining 54(50.9\%) were females. The mean age of the respondents was 53.48 \pm 14.77 years, twentyeighty respondents representing $26.4 \%$ were married at the time of the study, $15(14.2 \%)$ were single while the remaining $63(59.4 \%)$ were previously married. Thirty-seven $(34.9 \%)$ of the study subjects had no formal education and eighty-two (77.4\%) of the presentation at the clinic were having a diagnosis of hypertension, 8(7.5\%) were being treated for Rheumatic Heart Disease (RHD), 9(8.5\%) were diagnosed with cardiomyopathies, $3(2.8 \%)$ were diagnosed heart failure and $4(3.8 \%)$ had other cardiovascular diseases. The prevalence of depression was found to be $45.3 \%$ in this study, there was a statistically significant relationship between the diagnoses of depression and gender status $(\mathrm{p}=0.001)$, marital status $(\mathrm{p}=0.01)$, partner relationship $(\mathrm{p}=0.001)$, substance abuse $(\mathrm{p}=0.001)$. No statistically significant relationship was found between depression and occupational status $(\mathrm{p}=0.167)$, level of educational attainment $(\mathrm{p}=0.401)$, respondents' weight $(\mathrm{p}=0.06)$, and the nature of cardiovascular diagnoses $(\mathrm{p}=0.951)$. We recommended early detection and treatment of depression among patients with cardiovascular diseases.
\end{abstract}

Keywords: Cardiovascular, Depression, Prevalence

\section{Introduction}

Among patients with cardiovascular disease (CVD), depression is associated with rising medical costs ${ }^{1}$ increased health service utilization ${ }^{2}$, lost of productivity $^{3}$ and impairment in overall quality of life. ${ }^{4,5}$ It is also well established that depression is a risk factor for an increased incidence of CVD and a worse outcome in an existing CVD. ${ }^{6}$

The prevalence of depression among patients with CVD like hypertension and Coronary Artery Diseases (CAD) has been documented in various studies. In these populations, $20 \%$ to $40 \%$ have elevated depressive symptoms and $15 \%$ to $20 \%$ suffer from Major Depressive Disorder (MDD). ${ }^{7,8}$ Findings from another study by Barger et al, ${ }^{9}$ to study the effect of
Generalised Anxiety Disorder (GAD) and MDD on patients with coronary heart disease demonstrated that, $14 \%$ of the population had MDD. Similarly, a study by Baktash et al, has shown that, $41.9 \%$ of patients at cardiology clinic had suffered depression ${ }^{10}$ A study of psychiatric morbidity in hypertensive patients attending a cardiology out patients clinic in Nigeria shows that a total of $12.4 \%$ of the subjects were diagnosed with mood disorders $(6.2 \%$ current depression, $2.5 \%$ past major depressive syndrome and $3.7 \%$ of organic mood syndrome). ${ }^{11}$

It is imperative to note that the links between depression and cardiovascular diseases are complex and involve both biological and psychosocial mechanism. ${ }^{12}$ Depression, arrhythmias and CAD frequently co-occur because of shared behavioural and 
pathophysiological drivers like unhealthy lifestyles, autonomic dysregulation, endothelia dysfunction and inflammatory process that are intricately related to one another. ${ }^{13}$

Depression has been linked to increase levels of cytokines, specifically Interleukin-1 (IL-1) and Interleukin-6 (IL-6) both in patients with and without a history of CVD. ${ }^{14,15}$ Inflammatory cytokines on the other hands have been associated with atherosclerotic plaque formation and as such they contribute significantly to the pathogenesis of CAD, unstable angina, myocardial infarction and heart failure. Previous studies have provided evidence that inflammation is associated with elevated depressive symptoms and MDD is associated with the development of cardiac disease and cardiovascular mortality. For instance, in a population cohort study of 908 patients without known CVD, Kop et al, ${ }^{16}$ found that depression predicted cardiovascular mortality; controlling for inflammatory markers reduced the association by $12.7 \%$. Similarly, Vaccarino et al, ${ }^{17}$ in another study of 559 women with suspected cardiac ischemia, found that depression predicted cardiovascular events; controlling for inflammatory factors reduced this association by $20 \%$. These potential mechanisms may link inflammation, depression and CVD; the neural-immune interaction where reduced serotonin activity is known to be linked to increase cytokines and the subsequent effects on CVS. ${ }^{18,19}$ Also, elevated levels of inflammatory cytokines are associated with enhanced degradation of tryptophan, ${ }^{20}$ a precursor of serotonin and resulting to depressive disorders in patients with CVD.

Behavioural factors are also implicated in the occurrence of depression among patients with CVD. Patients with depression are less likely to engage in health promoting behaviours, including maintenance of a healthy diet, ${ }^{21,22}$ regular exercise, ${ }^{21,22}$ adherence to medications, ${ }^{21,22,23}$ stress reduction ${ }^{21}$ and completion of cardiac rehabilitation programs ${ }^{24,25}$ following MI. Non adherence to medication for a CVD and lowering of physical fitness are associated with an increased risk of cardiovascular events. ${ }^{26,27}$

Despite the existence of effective and safe treatment for depression in patients with CVD, depression remains under diagnosed and undertreated in this population. $^{28}$ For instance, in a study of post-MI patients, less than $15 \%$ of depressed patients were accurately identified by their treatment teams and only $11 \%$ received treatment with antidepressants. ${ }^{28}$ Given the increased morbidity and mortality associated with depression, it is important that these patients be more consistently identified and provided with adequate care to enhance longevity and improve their quality of life.

\section{Materials and Methods}

Site of study: The study was conducted at the Medical Outpatients Department (MOPD) of Benue State University Teaching Hospital (BSUTH), Makurdi. BSUTH is a tertiary institution and the MOPD of this hospital offers both secondary and tertiary health care services for patients referred from other departments of the hospital as well as other hospitals within and outside Benue State. Available records from the MOPD of BSUTH show that, there were about two thousands registered patients for the cardiology clinic at the time of the study, from June to August 2017.

Study instruments: The instruments consisted of the following;

1. A proforma designed by the authors to record the sociodemographic and clinical attributes of the subjects.

2. Hospital Anxiety and Depression Scale (HADS), a self assessment scale that was designed by AS Zigmond and RP Snaith in 1983 for detecting states of anxiety and depression in a setting of a medical outpatient clinic. ${ }^{29}$ The scale consists of 14 items that are divided into an anxiety and a depression subscale, each comprising seven questions rated on a scale that ranges from 0-3 depending on the severity of the problem described in the question. A subscale score below 7 is considered normal. A score of 7 to 21 is considered evidence of depression or anxiety depending on the subscale to be considered. The subscale for depression was considered for this study. This instrument has been validated and used in this environment. $^{30}$

3. The depression module of Structured Clinical Interview for Diagnostic and Statistical Manual IV (SCID) axis-1 disorders. The SCID is a diagnostic interview designed for used by mental health professionals. It assesses psychiatric disorders described in the fourth edition of the Diagnostic and Statistical Manual (DSM-IV) of the American Psychiatric Association. ${ }^{31}$ It is used for diagnostic evaluation research and training of 
mental health professionals. The instrument has been reported to have a good reliability. ${ }^{32}$

Procedure: With the informed consent of each consecutive subject, the proforma for sociodemographic and clinical attributes was administered by the authors. HADS was then administered and subjects with a score of 7 and above were interviewed by a psychiatrist using SCID for the diagnoses of depression. This was done on every clinic day until the sample size of 106 patients was obtained.

Exclusion criteria: This included subjects that were critically ill, those that could not give informed consent and subjects receiving treatment for other chronic medical conditions like diabetes mellitus, tuberculosis, cancer and human immunodeficiency virus infection.

Data analysis: The data was entered and analysed using the Statistical Package for Social Sciences (SPSS) version 22. Mean and standard deviations were used to describe continuous variables and proportions for categorical variables. The significance of observed differences in qualitative variables was determined using chi square tests while the level of statistical significance was set at $\mathrm{p}<0.05$.

\section{Results}

We recruited a total number of 106 subjects for this study, 54(50.9\%) were females and the remaining $52(49.1 \%)$ were males. The age ranges from 24 to 83 years with a mean age of $53.48 \pm 14.77$ years. The range, mean and standard deviation of the subjects' variables like age, height, weight, body mass index (BMI) and scores on the depression subscale of HADS are as presented in Table 1.

Twenty-eight $(26.4 \%)$ of the subjects were married at the time of the study while $15(14.2 \%)$ were single and the remaining $63(59.4 \%)$ were previously married (divorced, separated, widow, widower) as represented in Table 2. This table also shows that the common clinical diagnoses at the cardiology clinic was hypertension $(77.4 \%)$, followed by cardiomyopathies $(8.5 \%)$, Rheumatic heart diseases $(7.5 \%)$, heart failure (2.8\%), other CVD like coronary heart diseases and cor pulmonale $(3.8 \%)$. Depression was diagnosed in 48 subjects representing a prevalence rate of $45.3 \%$. There was a statistically significance relationship between the diagnosis of depression and gender status $(\mathrm{p}=0.001)$, marital status $(\mathrm{p}=0.01)$, partner relationship (0.001), substance abuse (0.001). No statistically significant relationship was found between depression and occupational status $(\mathrm{p}=0.167)$, level of educational attainment $(\mathrm{p}=0.401)$, respondents' weight $(\mathrm{p}=0.06)$, and the nature of diagnosis $(\mathrm{p}=0.951)$. This is presented in Table 3 .

Table 1: Ranges, means and standard deviations of subjects

\begin{tabular}{l|l|l}
\hline Variable & Range & Mean \\
\hline Age (years) & $24-83$ & $53.48 \pm 14.77$ \\
Height (metres) & $1.40-1.80$ & $1.61 \pm 0.09$ \\
Weight $(\mathrm{Kg})$ & $50-98$ & $71.51 \pm 12.04$ \\
BMI $\left(\mathrm{Kg} / \mathrm{m}^{2}\right)$ & $21.0-35.2$ & $27.42 \pm 3.57$ \\
HADS (D)score & $3-19$ & $7.72 \pm 4.59$ \\
\hline
\end{tabular}


Table 2: Frequency Distribution of Respondents' Socio-demographic and Clinical Variables

\begin{tabular}{|c|c|c|}
\hline Variable & Frequency $(\mathbf{N})$ & Percentage $(\%)$ \\
\hline \multicolumn{3}{|l|}{ Gender } \\
\hline male & 52 & 49.1 \\
\hline female & 54 & 50.9 \\
\hline total & 106 & 100.0 \\
\hline \multicolumn{3}{|l|}{ Weight (kg) } \\
\hline normal & 34 & 32.1 \\
\hline overweight & 43 & 40.6 \\
\hline obesity & 29 & 27.4 \\
\hline total & 106 & 100.0 \\
\hline \multicolumn{3}{|l|}{ Educational attainment } \\
\hline none & 37 & 34.9 \\
\hline primary & 29 & 27.4 \\
\hline secondary & 23 & 21.7 \\
\hline others & 17 & 16.0 \\
\hline total & 106 & 100.0 \\
\hline \multicolumn{3}{|l|}{ Occupational status } \\
\hline I \&II & 13 & 12.3 \\
\hline III \& IV & 36 & 34.0 \\
\hline V \& VI & 57 & 53.7 \\
\hline total & 106 & 100.0 \\
\hline \multicolumn{3}{|l|}{ Marital status } \\
\hline single & 15 & 14.2 \\
\hline married & 28 & 26.4 \\
\hline previously married & 63 & 59.4 \\
\hline total & 106 & 100.0 \\
\hline \multicolumn{3}{|l|}{ Partner relationship } \\
\hline excellent & 36 & 34.0 \\
\hline good & 20 & 18.9 \\
\hline poor & 50 & 47.2 \\
\hline total & 106 & 100.0 \\
\hline \multicolumn{3}{|l|}{ Substance used } \\
\hline present & 58 & 54.7 \\
\hline not present & 48 & 45.3 \\
\hline total & 106 & 100.0 \\
\hline \multicolumn{3}{|l|}{ Types of substances } \\
\hline alcohol & 50 & 47.2 \\
\hline multiple & 8 & 7.5 \\
\hline none & 48 & 45.3 \\
\hline total & 106 & 100.0 \\
\hline \multicolumn{3}{|l|}{ Diagnoses } \\
\hline hypertension & 82 & 77.4 \\
\hline rheumatic heart diseases & 8 & 7.5 \\
\hline heart failure & 3 & 2.8 \\
\hline cardiomyopathies & 9 & 8.5 \\
\hline others & 4 & 3.8 \\
\hline total & 106 & 100.0 \\
\hline
\end{tabular}




\begin{tabular}{|c|c|c|c|c|}
\hline \multicolumn{3}{|l|}{ Agbir et al., } & \multicolumn{2}{|c|}{ Depression among Patients attending Cardiology Clinic ... } \\
\hline Variable & Depression & No Depression & Total & Statistics \\
\hline \multicolumn{5}{|l|}{ Gender } \\
\hline male & 12 & 40 & 52 & $X^{2}=20.314$ \\
\hline female & 36 & 18 & 54 & $\mathrm{df}=1$ \\
\hline total & 48 & 58 & 106 & $p=0.001$ \\
\hline \multicolumn{5}{|l|}{ BMI } \\
\hline normal & 11 & 23 & 34 & $X^{2}=5.613$ \\
\hline overweight & 19 & 24 & 43 & $\mathrm{df}=2$ \\
\hline obesity & 18 & 11 & 29 & $\mathrm{p}=0.06$ \\
\hline total & 48 & 58 & 106 & \\
\hline \multicolumn{5}{|l|}{ Education } \\
\hline none & 9 & 8 & 17 & $X^{2}=2.941$ \\
\hline primary & 17 & 20 & 37 & $\mathrm{df}=3$ \\
\hline secondary & 15 & 14 & 29 & $\mathrm{p}=0.401$ \\
\hline tertiary & 7 & 16 & 23 & \\
\hline total & 48 & 58 & 106 & \\
\hline \multicolumn{5}{|l|}{ Occupation } \\
\hline I\&II & 9 & 4 & 13 & $\mathrm{X}^{2}=3.579$ \\
\hline III\&IV & 16 & 20 & 36 & $\mathrm{df}=2$ \\
\hline V\&VI & 23 & 34 & 57 & $\mathrm{p}=0.167$ \\
\hline total & 48 & 58 & 106 & \\
\hline \multicolumn{5}{|l|}{ Marital status } \\
\hline single & 2 & 13 & 15 & $X^{2}=9.269$ \\
\hline married & 11 & 17 & 28 & $\mathrm{df}=2$ \\
\hline prev. married & 35 & 28 & 63 & $\mathrm{p}=0.010$ \\
\hline total & 48 & 58 & 106 & \\
\hline \multicolumn{5}{|l|}{ Relationship } \\
\hline excellent & 6 & 30 & 36 & $X^{2}=22.537$ \\
\hline good & 8 & 12 & 20 & $\mathrm{df}=2$ \\
\hline poor & 34 & 16 & 50 & $\mathrm{p}=0.001$ \\
\hline total & 48 & 58 & 106 & \\
\hline \multicolumn{5}{|l|}{ Substance used } \\
\hline yes & 46 & 12 & 58 & $X^{2}=59.854$ \\
\hline no & 2 & 46 & 48 & $\mathrm{df}=1$ \\
\hline total & 48 & 58 & 106 & $\mathrm{p}=0.001$ \\
\hline \multicolumn{5}{|l|}{ Diagnoses } \\
\hline hypertension & 37 & 45 & 82 & $\mathrm{X}^{2}=0.001$ \\
\hline others & 10 & 13 & 24 & $\mathrm{df}=1$ \\
\hline total & 48 & 58 & 106 & $p=0.986$ \\
\hline
\end{tabular}




\section{Discussion}

Depression is known to be a common mental disorder among patients with cardiovascular diseases. It is highly underdiagnosed in this population and it is associated with a high rate of morbidity, mortality and impairment in the overall quality of life.

The prevalence rate of depression among patients attending the cardiology clinic of BSUTH in this study was found to be $45.3 \%$. This finding compares well with other studies that reported the prevalence of depression among this group to be high. For instance, in a descriptive study of depression and anxiety among cardiovascular outpatients clinic, Baktash et $a l^{10}$ found a prevalence rate of depression to be $41.9 \%$. Misland ${ }^{33}$ in another study, reported the prevalence of recurrent depression among vascular heart diseases to be $44 \%$. Similarly, the prevalence rate of depression in a study of patients with coronary artery diseases was reported to be between 31 to $45 \% .^{34}$ The high rate of depression reported in this study could be related to the site of study and the use of structured instrument with high validity and reliability for the diagnosis of depression in this population.

We found depression to be more common among females than male population with a female to male ratio of $3: 1$, a finding similar to the general trend of gender distribution of depression in the general population. This trend also compares well with another study of depression and anxiety among out patients with cardiovascular diseases where the rate of depression was significantly higher among women ${ }^{10}$. Hormonal factors, additional social stressors and issues of pregnancy may provide plausible explanations to this gender differences in the rates of depression.

In this study, depression was significantly associated with having a poor relationship with a sexual partner as well as those that were previously married (divorced, separated, widowed and widower). These findings suggest some relative protection offered against depression by maintaining a good social support and being married.

The study shows an over-representation of depression among subjects with a history of substance abuse notably alcohol. Alcohol was found to be the common substance of abuse in this study, a finding that agrees with previous studies. ${ }^{35}$ The comorbid condition of depression and substance abuse has been reported to affect drug adherence in patients with cardiovascular diseases like hypertension. The management of these CVD requires adherence to medications in order to improve the quality of wellbeing of the individual. Both psychiatric comorbidity and substance abuse can either singly or in synergy affects drugs adherence in this group of patients.

There was a preponderance of depression among subjects with overweight and obesity even though the difference was not statistically significant. Depression, overweight and cardiovascular diseases are known to be intricately related. A relationship between symptoms of depression and obesity has been noted consistently in studies of the psychological correlate and sequelae of obesity ${ }^{36,37}$ and obesity on the other hand is an established risk factor for hypertension ${ }^{36 .}$ Symptoms of depression are found to be associated with hypertension predominantly through a higher body mass index (BMI). ${ }^{38}$ Also, another previous study reported that a higher level of BMI was responsible partially not completely, for the effect of symptoms of depression on pathophysiological changes in relation to coronary heart diseases. ${ }^{39}$

There was no significant relationship between depression and occupational status as well as the level of educational attainment of respondents. A substantially good proportion of the respondents in this study attained at least the primary level of education. Considering the site of the study, it is possible that the respondents which are predominantly enlightened are likely to seek medical referrals to be treated at the tertiary health facility like BSUTH. A wider community based study may therefore be necessary to generalise this findings in this study.

High level of unemployment and underemployment in this part of the world may explain in part the overrepresentation of respondents with lower occupational status in this study, providing a plausible reason for lack of a relation between depression and occupational status as noticed in the study.

\section{Conclusion}

This study has shown that depression, a mood disorder, is common among patients with cardiovascular diseases. Many other related studies have supported the fact that depression is associated with a poor outcome among this population.

It is therefore recommended that adequate attention must be paid to early detection, diagnoses and treatment of depression among patients with CVD in order to improve their quality of life. 


\section{Limitation}

This was a cross-sectional descriptive study in a tertiary hospital setting which may limit the generalisation of its findings.

\section{Acknowledgement}

We thank the management of BSUTH and the department of internal medicine BSUTH for providing an enabling environment and support necessary for this study. We are also extending our profound gratitude to the nurses at MOPD and staff of records department BSUTH for their understanding and support during this study.

\section{References}

1. Sullivan M., Simon G., Spertus J., Russo J. Depression related costs in heart failure care. Arch Intern Med. 2002; 162: 1860-1866.

2. Egede LE. Major depression in individuals with chronic medical disorders: prevalence, correlates and association with health resource utilization, lost productivity and functional disability. Gen Hosp Psychiatry. 2007; 29: 409-416

3. Dickson VV, Howe A, Deal J, McCarty MM. The relationship of work, self care and quality of life in a sample of older working adults with cardiovascular disease. Heart Lung. 2012; 41: 514.

4. Mensah GA, Brown DW. An overview of cardiovascular disease burden in the United States. Health Aff. 2007; 26: 38-48.

5. Djarv T, Wikman A. Lagergren P. Number and burden of cardiovascular diseases in relation to health-related quality of life in a cross-sectional population -based cohort study. BMJ Open. 2012; 2: $\mathrm{e} 001554$.

6. Nicholson A, Kuper $H$, Hemingway $H$. Depression as an aetiologic and prognostic factor in coronary heart disease: a meta-analysis of 6362 events among 146,538 participants in 54 observational studies. Eur Heart J. 2006; 27: 2763-2774.

7. Thombs BD, Bass EB, Ford DE. Prevalence of depression in survivors of acute myocardial infarction. J Gen Itern Med. 2006; 21: 30-38.

8. Rutledge T, Reis VA, Linke SE. Depression in heart failure, a meta-analytic review of prevalence, intervention effects and associations with clinical outcomes. J m Coll Cardiol. 2006; 48: 1527-1537.

9. Sleven DB, Summer JS. Does Generalised Anxiety Disorder predict Coronary Heart Disease risk factors independently of Major Depressive Disorder? Journal of Affective Disorders. 2005; 88:87-91.

10. Baktash B, Shakila Y, Mahtab B. Depression and anxiety in cardiovascular outpatient clinic: A descriptive study. Iran J Psychiatry. 2011; 6(3):125-127.

11. Oshodi YO, Adeyemi JD, Oke DA, Seedat S. Psychiatric morbidity in hypertensives attending a cardiology outpatient clinic in West Africa. Nigerian Journal of Clinical Practice. 2012; 15:84-88.

12. Huffman JC, Celano CM, Beach SR. Depression and cardiac disease: epidemiology, mechanisms, and diagnoses. Cardiovasc Psychiatry Neurol. 2013https://www.hindawi.com/journals/cpn/2013/ 695925/. Accessed November 1, 2016.

13. Alluder C. Anxiety as a risk factor in cardiovascular disease. Curr Opin Psychiatry. 2016; 29:13-17.

14. Pizzi C, Manzoli L, Mancini S, Bedetti G, Fontana F, Costa GM. Autonomic nervous system, inflammation and preclinical carotid atherosclerosis in depressed subjects with coronary risk factors. Atherosclerosis. 2010; 212(1):292-298.

15. Howren MB, Lamkin DM, Suls J. Associations of depression with c-reactive protein, IL-1, and IL-6: a meta-analysis. Psychosomatic Medicine. 2009; 71(2):171-186.

16. Kop WJ, Stein PK, Tracy RP, Barzilay JI, Schulz $\mathrm{R}$, Gottdiener JS. Autonomic nervous system dysfunction and inflammation contribute to the increased cardiovascular mortality risk associated with depression. Psychosomatic Medicine. 2010;72(7):626-635.

17. Vaccarino V, Johnson BD, Sheps DS, et al. Depression, inflammation, and incident cardiovascular disease in women with suspected coronary ischemia. The national heart, lung, and blood institutute-sponsored WISE study. Journal of the American College of Cardiology. 2007;50(21):2044-2050.

18. Katafuchi T, Kondo T, Take S, Yoshimura M. Brain cytokines and the 5-HT system during poly I:C-induced fatigue. Annals of the New York Academy of Science. 2006;1088:230-237. 
19. Katafuchi T, Kondo T, Take S, Yoshimura M. Enhanced expression of brain interferon and serotonin transporter in immunologically induced fatigue in rats. European Journal of Neuroscience, 2005; 22(11):2817-2826.

20. Wirleitner B, Rudzite V, Neurauter G, et al. Immune activation and degradation of tryptophan in coronary heart disease. European Journal of Clinical Investigation. 2003;33(7):550-554.

21. Ziegelstein RC, Fauerbach JA, Stevens SS, Romanelli J, Richter DP, Bush DE. Patients with depression are less likely to follow recommendations to reduce cardiac risk during recovery from a myocardial infarction. Archives of Internal Medicine. 2000; 160(12):1818-1823.

22. Bauer LK, Caro MA, Beach SR, et al. Effects of depression and anxiety improvement on adherence to medication and health behaviours in recently hospitalised cardiac patients. The American Journal of Cardiology. 2012; 109(9):1266-1271.

23. May HT, Sheng X, Catinella AP, Horne BD, Carlquist JF, Joy E. Antilipidemic adherence postcoronary artery disease diagnosis among those with and without an ICD-9 diagnosis of depression. Journal of Psychosomatic Research. 2010;69(2):169-174.

24. Casey E, Hughes JW, Waechter D, Josephson R, Rosneck J. Depression predicts failure to complete phase -II cardiac rehabilitation. Journal of Behavioral Medicine. 2018;31(5):421-431.

25. McGrady A, McGinnis R, Badenhop D, Bentle M, Rajput M. Effects of depression and anxiety on adherence to cardiac rehabilitation. Journal of Cardiopulmonary Rehabilitation and Prevention. 2009;29(6):358-364.

26. Gehi AK, Ali S, Na B, Whooley MA. Selfreported medication adherence and cardiovascular events in patients with stable coronary heart disease: the heart and soul study. Archives of Internal Medicine. 2007; 167(16):1798-1803.

27. Wessel TR, Arant CB, Olson MB, et al. Relationship of physical fitness versus body mass index with coronary artery disease and cardiovascular events in women. The Journal of the American Medical Association. 2004;292(10):1179-1187.

28. Huffman JC, Smith FA, Blais MA, Beiser ME, Januzzi JL, Fricchione GL. Recognition and treatment of depression and anxiety in patients with acute myocardial infarction. The American Journal of Cardiology. 2006;98(3):319-324.

29. Zigmond AS, Snaith RP. The Hospital Anxiety and Depression Scale. Acta Psychiatrica Scandinavica. 1983;67:361-370.

30. Abiodun OA. A validity study of the Hospital Anxiety and Depression Scale in general hospital units and a community sample in Nigeria. Bri J Psychiatry. 1994;169:669-672.

31. American Psychiatric Association. Diagnostic and Statistical Manual of Mental Disorders. Fourth edition (DSM-IV). Washington DC: APA; 1994.

32. Riskind JH, Beck AT, Berchick RJ, Brown G, Steer RA. Reliability of DSM III diagnoses for major depression and generalised anxiety disorder using the Structured Clinical Interview for DSM III. Arch Gen Psychiatry. 1987;44:817-20.

33. Freedland KE, Carney RM, Lustman PJ, Rich MW, Jaffe AS. Major depression in coronary artery diseases patients with vs without a prior history of depression. Psychosom Med. 1992;54:416-421.

34. Celano CM, Huffman JC. Depression and cardiac disease: a review. Cardiology in Review. 2011;19(3):130-142.

35. Nkporbu AK, Stanley PC. Psychiatric morbidity and substance use correlated with drug compliance among subjects with essential hypertension attending the outpatient clinic of University of Port Harcourt Teaching Hospital. MOJ Addict Med Ther. 2018;5(3):148-158.

36. Carpenter KM, Hasin DS, Allison DB, Faith MS. Relationship between Obesity and DSM-IV Major Depressive Disorder, Suicide ideation and Suicide attempts: results from a general population study. Am J Public Health. 2000;90:251-257.

37. Istvan J, Zavela K, Weidner G. Body weight and psychological distress in NHANESI. Int J Obes Relat Metab Disord 1992; 16:999-1003.

38. Azad AK, Paul KW, Khan MM, Jeanette G, Wei C. Association of symptoms of depression and obesity with hypertension: The Bogalusa Heart Study. American Journal of Hypertension. 2006:19(6);639-645.

39. Miller GE, Stetler CA, Carney RM, Freedland $\mathrm{KE}$, Banks WA. Clinical depression and inflammatory risk markers for coronary heart disease. Am J Cardiol. 2002;90:1279-1283. 